\title{
Iliac Artery Occlusion in a Patient With Allograft Renal Transplant Causing Refractory Heart Failure and Simulating Renal Artery Stenosis With Solitary Kidney
}

\author{
Hetavi Mahida ${ }^{\mathrm{a}, \mathrm{b}}$, Attiya Haroon ${ }^{\mathrm{a}}$, Firas Ajamª ${ }^{\mathrm{a}}$, Ana Gubeladze ${ }^{\mathrm{a}}$, Dawn Calderon ${ }^{\mathrm{a}}$, \\ Renato Apolito ${ }^{\text {, }}$ Mohammad A. Hossain ${ }^{\mathrm{a}}$
}

\begin{abstract}
Renal dysfunction after transplant is rare and associated iliac artery stenosis leading to refractory heart failure is extremely rare. Renal artery stenosis in a solitary kidney is known to lead to severe hypertension and acute pulmonary edema. Revascularization with percutaneous transluminal angioplasty of the solitary renal artery stenosis, or its equivalent, can resolve this syndrome and normalize blood pressure and volume status, though the event of hypertension is thought to occur within 15 days of transplant. We describe a case here of iliac artery stenosis with refractory acute heart failure, severe hypertension and threatened renal allograft transplant occurring 3 years after the transplant. Subsequent diagnosis and revascularization were curative.
\end{abstract}

Keywords: Iliac artery stenosis; Solitary kidney; Transplant; Hypertension

\section{Introduction}

Most studies have shown that all renovascular hypertension with transplant renal artery stenosis (TRAS) occurs most commonly at the anastomosis site and less commonly in the distal transplanted renal artery [1]. The mechanism of solitary iliac artery stenosis in a transplant patient causing heart failure (HF) is similar to renal artery stenosis that causes neurohormonal activation leading to fluid retention and volume overload [2]. We report a case of unilateral iliac artery stenosis in a patient with solitary kidney causing refractory HF with preserved ejection fraction and improvement of $\mathrm{HF}$ after revascularization of occluded iliac artery.

Manuscript submitted November 19, 2018, accepted December 26, 2018

aDepartment of Medicine, Jersey Shore University Medical Center, Hackensack Meridian Health, Neptune, NJ 07753, USA

${ }^{b}$ Corresponding Author: Hetavi Mahida, Department of Medicine, Jersey Shore University Medical Center, Hackensack Meridian Health, Neptune, NJ 07753, USA. Email: mahidahetavi@gmail.com

doi: https://doi.org/10.14740/jmc3218

\section{Case Report}

A 70-year-old woman with history of hypertension (HTN), type 2 diabetes mellitus (DM2), and end-stage renal disease (ESRD) from granulomatosis with polyangiitis status post cadaver kidney transplant in 2008 presented to the hospital after having increasing dyspnea, orthopnea and paroxysmal nocturnal dyspnea. Her American College of Cardiology (ACC)/ American Heart Association (AHA) Task Force was stage D and New York Heart Association (NYHA) class IV. She had history of multiple previous admissions for similar presentation and was treated conservatively for HF. Social history includes formal smoking, one pack per day, and she quit 19 years ago. On physical examination blood pressure was $176 / 90 \mathrm{~mm}$ $\mathrm{Hg}$, pulse rate 94, respiratory rate 30 , protodiastolic S3 sound heard, Killip class III rales, and there was trace edema of lower extremities $2^{+}$bilaterally. On laboratory investigation (Table 1), pro-brain natriuretic peptide (Pro-BNP) was highly elevated to $3,900 \mathrm{pg} / \mathrm{mL}$, first troponin was negative, second troponin was 1.19 , repeat troponin started to trend down, creatinine level was $2.4 \mathrm{mg} / \mathrm{dL}$, elevated from previous reading, she had estimated glomerular filtration rate (eGFR) 20 stage IV chronic kidney disease (CKD), and progressive deterioration of renal function. Her EKG was unremarkable but chest X-ray showed bilateral vascular congestion consistent with HF. Chronic rejection with secondary volume overload was also considered in differential diagnosis. Transthoracic echocardiogram (TTE) showed ejection fraction to be 55\%, left ventricular hypertrophy and significant diastolic dysfunction. Renal ultrasound (US) showed small, echogenic atrophic native kidney compatible with CKD, and it also showed transplant kidney in the right lower quadrant with no evidence of renal artery stenosis. Cardiac catheterization was done and showed complete occlusion of right common iliac artery on the side of the allopathic renal transplant anastomosis with a $120 \mathrm{~mm} \mathrm{Hg}$ gradient relative to the central systemic arterial blood pressure, thereby under-perfusing the right kidney transplant (Fig. 1). As a result of her refractory HF severe HTN, and threatened renal allograft failure despite optimal medical management, it was decided to perform percutaneous revascularization of the total right common iliac artery occlusion.

Ipsilateral stenting of the right common iliac artery, suc- 
Table 1. Clinical, Catheterization and Serum Chemistry Comparison Pre- and Post- Stenting of Both Common Iliac Arteries

\begin{tabular}{lll}
\hline Parameters & Pre-operative & Post-operative day 1 \\
\hline BNP $(\mathrm{pg} / \mathrm{mL})$ & 3,926 & 800 \\
NYHA class & $\mathrm{IV}$ & $\mathrm{I}$ \\
Heart rate & 94 & 70 \\
Peak iliac artery pressure gradient $(\mathrm{mm} \mathrm{Hg})$ & 120 & 0 \\
Serum creatinine $(\mathrm{mg} / \mathrm{dL})$ & 2.4 & 1.23 \\
eGFR $\left(\mathrm{mL} / \mathrm{min} / 1.73 \mathrm{~m}^{2}\right)$ & 20 & 44 \\
Serum sodium $(\mathrm{mmol} / \mathrm{L})$ & 134 & 136 \\
Antihypertensive drugs & 2 & 0 \\
\hline
\end{tabular}

cessfully placed with an $8 \times 60 \mathrm{~mm}$ SMART (shape memory alloy recoverable technology) nitinol self-expanding stent further expanded with a $7 \mathrm{~mm}$ balloon (Fig. 2). Post-procedure abdominal aortography and digital subtraction angiography showed retrograde filling of the collateral's vessels with immediate return of strong femoral pulse. No residual arterial pressure was seen at that time. The patient was continued on short-acting antihypertensive agents and diuretics. Her kidney functions were monitored closely. On next day, her dyspnea improved significantly, blood pressure remained well controlled without any medications, serum creatinine level returned to base line, and Pro-BNP level dropped to normal. Repeat echo revealed markedly decreased tricuspid valve peak gradient to $25 \mathrm{mg}$, suggesting improved left ventricular filling pressure. The patient was closely observed for any thromboembolic event, retroperitoneal hemorrhage, dissection of the renal artery, embolization of dislodged fragments, and immediate hypotension preceding the catheterization. There were no complications and she was subsequently discharged home after 2 days with outpatient follow-up with cardiologists.

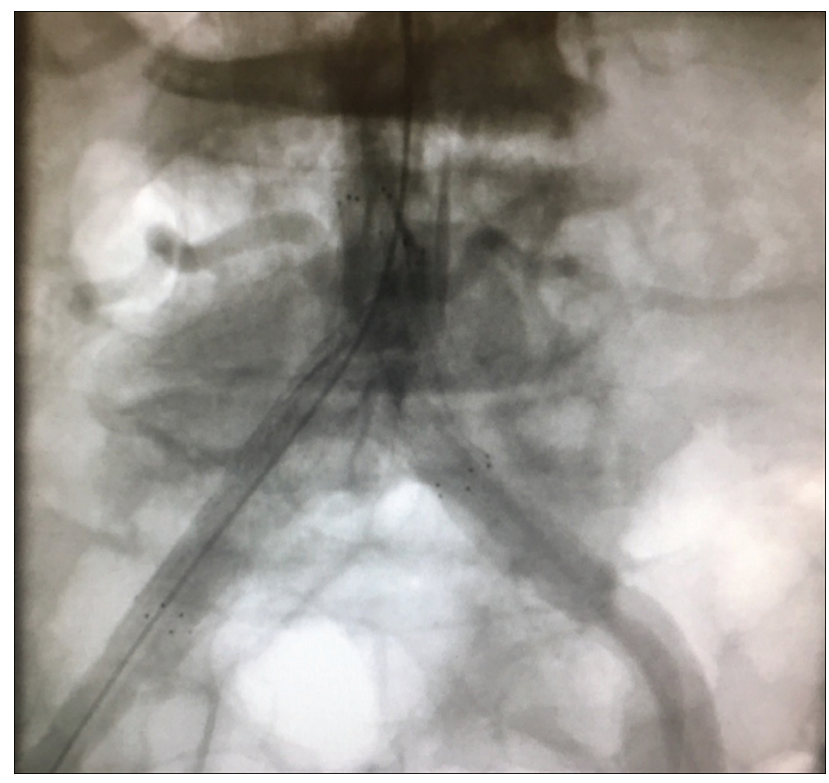

Figure 1. No flow found in the right iliac artery.

\section{Discussion}

HF occurring from bilateral renal artery stenosis or unilateral renal artery stenosis has a known cause [3-6]. But HF following renal transplant and common iliac artery stenosis is a rare and unique presentation. Stenosis of the iliac artery can occur proximal or distal to the anastomosis site, and stenosis above the anastomosis can be easily missed on routine diagnostic test. Here in this case the renal transplant was anastomosed with common iliac artery and there was bilateral iliac artery stenosis from atherosclerotic disease. Iliac artery stenosis after the renal allograft is rare, but some evidence is there for iliac artery stenosis causing HTN post-transplant but insufficient information on refractory HF post-transplant.

It has been reported in the past that uncontrolled HTN developed either acutely (immediately after transplant) or

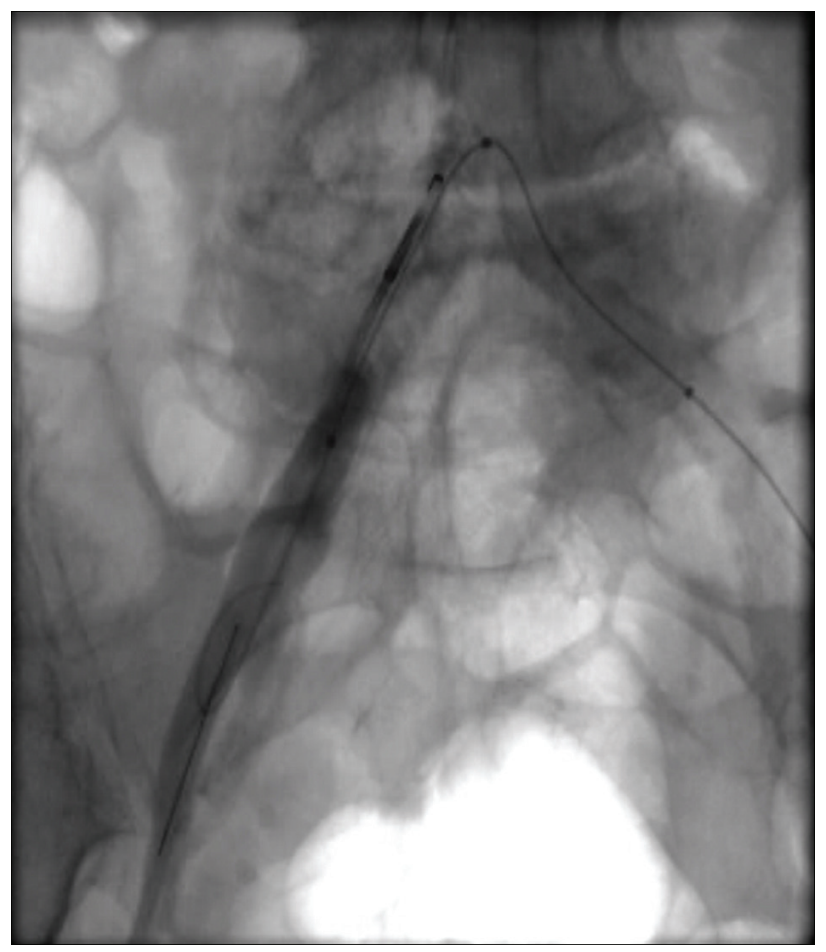

Figure 2. The stent placement with retrograde flow. 
chronically (after 3 months) can be successfully managed after transluminal balloon angioplasty (PTA) [7]. However in our case, patient developed HTN after 3 years with worsening HF. Doppler US radiology studied prospectively 237 kidney transplant patients by Aguera et al, finding 13 vascular complications, of which one involved stenosis of the iliac artery requiring revascularization [8]. Merkus et al examined patient with clinical suspicion of renal artery stenosis which include 131 hypertensive (diastolic blood pressure $(\mathrm{DBP})=90 \mathrm{~mm}$ $\mathrm{Hg}$ ) allograft recipients with Doppler US, and found four cases of iliac artery stenosis, two of which occurred within 15 days of transplant [7]. Most commonly involved site is the proximal portion in the distal branches of the transplanted artery. Development of TRAS, in the early post-transplant period, occurs most commonly at the anastomosis and may involve the iliac artery, the etiology of which most likely is iatrogenic factors or dissection of the transplanted artery [9]. Atherosclerosis is one of the causes of iliac artery stenosis in late post-transplant period, which could be pre-existing or new $[9,10]$.

In our case the patient had NYHA class IV HF with atherosclerotic iliac artery which leads to cardiorenal syndrome. Management with PTA showed excellent results. Renogram with 99mTc-diethylenetriamine pentaacetic acid (99mTcDTPA) can be used to diagnose, but atherosclerotic disease may sometime be difficult to diagnose [11].While diagnosing a patient with refractory HF following criteria can be helpful including history of renal transplant, baseline creatinine, medications (angiotensin-converting enzyme inhibitor/angiotensin receptor blockers (ACEI/ARBs), beta-blockers (BBs), diuretics, spironolactone, and more than five medications for blood pressure), HF (no other cause can be explained), peripheral pulses and ankle brachial index [12]. Investigation should include duplex Doppler US and femoral artery waveform [13, 14], plasma renin activity, and catheterization.

This patient who was having recurrent refractory HF uncontrolled on medication was hemodynamically stable with improvement in the left ventricular filling pressure and pulmonary arterial pressure and reduction in diuretic as well as antihypertensive use after the revascularization. Iliac artery angioplasty for patients with renovascular HTN and its improvement were shown by Grossman et al and Felten et al after short-term follow-up $[10,11]$. Our patient showed improvement with no further admission for pulmonary edema or hypertensive crisis within 1 year of follow-up.

\section{Conclusions}

While dealing with the etiology of HF thorough search should be done for atherosclerotic artery disease such as iliac artery stenosis especially in a patient with history of renal allograft transplant. Revascularization helps with symptoms management and also decreases the need for medication.

\section{Statement of Ethics}

The authors have no ethical conflicts to disclose.

\section{Funding Sources}

This project was not supported by any grant or funding agencies.

\section{Consent}

The patient described in the case report had given informed consent for the case report to be published.

\section{Conflict of Interest}

The authors declare that there is no conflict of interest regarding the publication of this paper.

\section{References}

1. Roberts JP, Ascher NL, Fryd DS, Hunter DW, Dunn DL, Payne WD, Sutherland DE, et al. Transplant renal artery stenosis. Transplantation. 1989;48(4):580-583.

2. Koushik RS, Matas AJ, Rosenberg ME. Iliac artery stenosis masquerading as diuretic resistant congestive heart failure. Clin Transplantation. 2000;14:11-13.

3. Messerli FH, Bangalore S, Makani H, Rimoldi SF, Allemann Y, White CJ, Textor S, et al. Flash pulmonary oedema and bilateral renal artery stenosis: the Pickering syndrome. Eur Heart J. 2011;32(18):2231-2235.

4. van den Berg DT, Deinum J, Postma CT, van der Wilt GJ, Riksen NP. The efficacy of renal angioplasty in patients with renal artery stenosis and flash oedema or congestive heart failure: a systematic review. Eur J Heart Fail. 2012;14(7):773-781.

5. Parikh SA, Shishehbor MH, Gray BH, White CJ, Jaff MR. SCAI expert consensus statement for renal artery stenting appropriate use. Catheter Cardiovasc Interv. 2014;84(7):1163-1171.

6. Vensel LA, Devereux RB, Pickering TG, Herrold EM, Borer JS, Laragh JH. Cardiac structure and function in renovascular hypertension produced by unilateral and bilateral renal artery stenosis. Am J Cardiol. 1986;58(7):575-582.

7. Merkus JW, Hoitsma AJ, van Asten WN, Zeebregts CJ, van der Vliet JA, Strijk SP, Koene RA, et al. EchoDoppler diagnosis of renal allograft artery stenosis. Clin Transplant. 1995;9(5):383-389.

8. Aguera Fernandez LG, Zudaire JJ, Isa WA, Sanchez de la Muela PL, Rosell D, de Castro F, Robles JE, et al. [Vascular complications in 237 recipients of renal transplant from cadaver]. Actas Urol Esp. 1992;16(4):292-295.

9. Merkus JW, van Asten WN, Hoitsma AJ, Buskens FG, Koene RA, Skotnicki SH. Iliac artery stenosis after kidney transplantation. Acta Chir Belg. 1993;93(5):242-248.

10. Felten H, Kuhn K. Renovascular hypertension after renal transplantation - don't look only after the graft artery. Nephrol Dial Transplant. 1996;11(7):1383-1384.

11. Gossmann J, Liermann D, Scheuermann EH, Lenz T. Cur- 
able hypertensive renal failure due to iliac artery stenosis in a kidney transplant recipient. Nephrol Dial Transplant. 1997;12(3):596-598.

12. Weigele JB. Iliac artery stenosis causing renal allograftmediated hypertension: angiographic diagnosis and treatment. AJR Am J Roentgenol. 1991;157(3):513-515.

13. Langsfeld M, Nepute J, Hershey FB, Thorpe L, Auer AI,
Binnington HB, Hurley JJ, et al. The use of deep duplex scanning to predict hemodynamically significant aortoiliac stenoses. J Vasc Surg. 1988;7(3):395-399.

14. Sawchuk AP, Flanigan DP, Tober JC, et al. A rapid, accurate nonivassive technique for diagnosing critical and subcritical stenosis in aortoiliac arteries. J Vasc Surg. 1990;12(2):158-167. 